\title{
KAJIAN PEMASARAN IKAN LELE (Clarias Sp) DALAM MENDUKUNG INDUSTRI PERIKANAN BUDIDAYA (Studi Kasus di Kabupaten Boyolali, Jawa Tengah)
}

\author{
Riesti Triyanti dan Nensyana Shafitri \\ Balai Besar Penelitian Sosial Ekonomi Kelautan dan Perikanan \\ JI. KS. Tubun Petamburan VI Jakarta 10260 \\ Telp. (021) 53650162, Fax. (021)53650159 \\ Email: : riesti_ok@yahoo.com
}

Diterima 21 Oktober 2012 - Disetujui 3 Desember 2012

\begin{abstract}
ABSTRAK
Penelitian bertujuan untuk mengkaji saluran pemasaran ikan lele di Kabupaten Boyolali. Penelitian juga dilakukan untuk mengkaji besarnya biaya, keuntungan, margin pemasaran serta efisiensinya. Penelitian menggunakan metode survei. Data yang digunakan adalah data primer yang diambil pada bulan April 2012 dengan teknik wawancara, pencatatan dan observasi. Teknik pengambilan sampel pembudidaya dilakukan secara random sampling; sedangkan sampel pedagang diambil secara snowball sampling. Analisis data dilakukan secara deskriptif dan cost margin analysis. Hasil penelitian menunjukkan bahwa ada empat pola rantai pemasaran ikan lele dengan rantai yang panjang di saluran I dan II dan rantai terpendek di rantai III. Biaya dan keuntungan terbesar untuk penjualan lele hidup terdapat di saluran pemasaran I, sedangkan margin pemasaran terkecil untuk penjualan lele hidup terdapat di saluran pemasaran II. Ketiga saluran pemasaran lele hidup sudah efisien dengan nilai farmer's share terbesar pada saluran II yaitu $87,34 \%$; sedangkan saluran IV memiliki nilai farmer's share terkecil sebesar 8,95\%. Hasil penelitian efisiensi saluran pemasaran lele diharapkan dapat dijadikan sebagai dasar pertimbangan peningkatan nilai tambah dan daya saing produk perikanan budidaya sehingga dapat meningkatkan pendapatan pembudidaya dan industri pengolahan.
\end{abstract}

Kata Kunci: pemasaran lele, margin, keuntungan, efisiensi pemasaran, farmer's share

\section{Abstract: Marketing Analysis Catfish of to Support Aquaculture Industry (Case Study on Boyolali District, Central Java). By: Riesti Triyanti and Nensyana Shafitri.}

This study aimed to assess marketing channels of catfish in Boyolali district. Research was carried out to access costs, benefits, marketing margin and their efficiencies. The research employs survey method. Data were collected in April 2012 using interview techniques, recording and observation. Farmers samples technique used random sampling, whereas traders samples were selected by snowball sampling technique. Data were analyzed using cost margin analysis. Results of this study showed that there were four patterns of catfish marketing chain with the largest chain were in the channel I and II and the shortest chain was in the chain III. The biggest costs and benefits of selling live catfish were in marketing channel I, while the smallest ones was in the marketing channels catfish II. All the three live marketing chanel were efficient with the biggest and smallest value of farmer's share of 87,34\% (marketing chanel II) and 8,95\% (marketing chanel IV), respectively. Results of the study were expected to be used as a basis for increasing value added and competitiveness of fish cultured product so that fish farmers and fish processors income can be increased.

Keywords: : cathfish marketing, margin, profit, marketing efficiency, farmer's share 


\section{PENDAHULUAN}

Indonesia memiliki posisi sebagai produsen hasil perikanan sekaligus juga konsumen produk perikanan dunia. Posisi Indonesia sebagai negara konsumen yang cukup besar dengan penduduk saat ini sekitar 240 juta orang merupakan pasar potensial bagi berbagai produk dunia termasuk produk perikanan. Untuk itu, produk perikanan nasional harus diterima menjadi tuan di negeri sendiri sekaligus sebagai dasar untuk masuk dan berkembang di pasar negara lain.

Kebijakan industrialisasi merupakan strategi Kementerian Kelautan dan Perikanan (KKP) untuk meningkatkan nilai tambah pelaku usaha perikanan. Dalam industrialisasi perikanan, keterkaitan antara hulu (atau di kalangan produksi bahan baku) tidak berjalan baik bila tidak ada daya tarik dari industri di hilir, yaitu pengolahan dan pemasaran. Untuk mewujudkan industrialisasi maka dilakukan perbaikan hulu hingga hilir dengan memprioritaskan peningkatan daya saing dan nilai tambah melalui program peningkatan "supply chain and value chain management" dengan empat strategi yaitu meningkatkan produksi perikanan budidaya melalui berbagai program, diantaranya pengadaan benih, saprokan, dan program bantuan (PUMP), meningkatkan produksi perikanan budidaya, meningkatkan produksi produk olahan bernilai tambah tinggi melalui peningkatan kapasitas UKM dan industrialisasi pengolahan dan mengembangkan industri pendukung serta industri terkait lainnya.

Peningkatan produksi perikanan seperti yang tertuang dalam 4(empat) strategi KKP untuk mewujudkan industrialisasi menjadikan perikanan budidaya menjadi salah satu tulang punggung dan ujung tombak dalam pelaksanaan program industrialisasi dengan berpegang pada penerapan Cara Budidaya Ikan Yang Baik (CBIB) atau Good Aquaculture Practices (GAP). Adapun fokus peningkatan produksi nantinya dilakukan pada 4 (empat) komoditas unggulan yakni udang, rumput laut, patin dan bandeng, sedangkan lele meskipun bukan komoditas unggulan industrialisasi namun potensi konsumsi lele yang mampu menembus konsumen menengah keatas, sehingga lele pun sekarang telah menjadi komoditas perikanan bergengsi yang perlu dipacu produksinya sehingga dapat menjadi komoditas yang berdaya saing dalam pasar domestik.

Perkembangan produksi ikan lele di Indonesia meningkat secara signifikan selama 2006-2010, dengan kenaikan rata-rata setiap tahun sebesar 39,66 persen. Pada tahun 2010, produksi ikan lele meningkat drastis dari 144.755 ton pada tahun 2009 menjadi 242.811 ton pada tahun 2010 atau naik sebesar 67,74\% (Direktorat Jenderal Perikanan Budidaya, 2010). Adapun propinsi yang menjadi sentra produksi lele di Indonesia antara lain Jawa Barat (Kabupaten Bogor dan Indramayu), Jawa Tengah (Kabupaten Banyumas, Sukoharjo, Boyolali, dan Purbalingga), Jawa Timur (Kabupaten Tulungagung dan Jombang) dan D.I Yogyakarta (Kabupaten Sleman dan Kulonprogo).

Kabupaten Boyolali memiliki potensi di bidang perikanan khususnya air tawar. Berdasarkan kondisi alam yang ada, kemudian ditetapkan potensi kawasan budidaya perikanan di Desa Tegalrejo, Kecamatan Sawit atau lebih dikenal sebagai Kampung Lele yang menjadi sentra pembesaran lele serta Kecamatan Banyudono dan Kecamatan Teras menjadi wilayah pendukung (hinterland) atau menjadi sentra pembenihan. Jumlah produksi Kabupaten Boyolali selama 5 (lima) tahun terakhir sebesar 44.735 ton (Dinas Kelautan dan Perikanan Kabupaten Boyolali, 2012).

Pemasaran produk adalah satu komponen pasca produksi yang perlu mendapatkan perhatian lebih karena pemasaran merupakan salah satu kunci dalam pengembangan usaha. Sebagai komoditas yang mudah rusak (perisable), pemasaran lele harus mendapatkan perhatian yang serius. Panjang pendeknya saluran pemasaran akan menentukan kualitas lele sehingga akan berpengaruh terhadap besar kecilnya biaya, keuntungan, margin pemasaran serta efisiensinya. Berdasarkan permasalahan di atas, 
maka tulisan ini bertujuan untuk mengetahui saluran pemasaran yang digunakan dalam pemasaran lele di Kabupaten Boyolali, besarnya biaya, keuntungan, margin pemasaran serta efisiennya.

\section{METODOLOGI}

\section{Lokasi dan Waktu Penelitian}

Waktu penelitian dilaksanakan pada bulan April 2012, di Kabupaten Boyolali, Jawa Tengah. Dasar pemilihan lokasi penelitian merupakan sentra produksi ikan yaitu pembenihan dan pembesaran serta pengolahan selain itu juga tempat transaksi jual beli ikan.

\section{Jenis dan Sumber Data}

Jenis data yang dikumpulkan adalah data sekunder dan primer. Data sekunder, yaitu data jumlah produksi, jumlah pembudidaya, dan jumlah rumah tangga perikanan Tahun 2006-2011, kebutuhan dan ketersediaan input produksi, jenis sarana dan prasarana pendukung usaha perikanan budidaya, Kabupaten dalam Angka dan Kecamatan dalam Angka (BPS), dan data sekunder berupa buku, dokumen, laporan, artikel, jurnal yang terkait dengan pemasaran lele yang diperoleh melalui instansi dan lembaga terkait serta melalui studi literatur. Data primer diperoleh melalui observasi langsung di lapang dan wawancara langsung dengan responden dengan menggunakan kuesioner di beberapa kecamatan di Kabupaten Boyolali, antara lain: karakteristik sosial ekonomi responden pembudidaya dan pedagang, data usaha pembenihan dan pembesaran lele, kegiatan pemasaran, tujuan pemasaran, dan informasi harga lele dari hulu hingga hilir.

\section{Metode Pengumpulan Data}

Pengumpulan data sekunder dilakukan dengan cara mencatat dan mempelajari dokumen tertulis dan laporan-laporan, sedangkan data primer diperoleh melalui survey dan observasi. Penentuan lokasi penelitian menggunakan metode purposive sampling, yaitu berdasarkan penetapan kawasan minapolitan. Penentuan responden untuk pembenih dan pembudidaya, menggunakan metode simple random sampling, sedangkan responden pedagang menggunakan metode snowball sampling. Jumlah responden secara rinci disajikan pada Tabel 1.

\section{Metode Analisis Data}

Metode analisis biaya pemasaran dan margin pemasaran ditingkat lembaga dalam saluran pemasaran menggunakan alat analisis biaya dan margin pemasaran (cost margin analysis) yaitu dengan menghitung besarnya biaya, keuntungan, dan margin pemasaran pada tiap lembaga perantara pada berbagai saluran pemasaran.

Tabel 1. Metode Sampling dan Responden dalam Penelitian.

Table 1. Sampling Method and Type of Respondents in the Research.

\begin{tabular}{ll}
\hline $\begin{array}{c}\text { Metode Sampling/ } \\
\text { Sampling Methods }\end{array}$ & \multicolumn{1}{c}{$\begin{array}{c}\text { Jenis Responden/ } \\
\text { Type of Respondents }\end{array}$} \\
\hline Purposive Sampling & $\begin{array}{l}\text { Stakeholders (Dinas Peternakan dan Perikanan } \\
\text { Kabupaten Boyolali)/Department of Livestock and } \\
\text { Fisheries in Boyolali District }\end{array}$ \\
Simple Random Sampling & $\begin{array}{l}\text { Pembenih/Seeder } \\
\text { Snowball Sampling* }\end{array}$ \\
\hline
\end{tabular}

*) Teknik pengambilan informan secara snowball sampling tergantung pada key-informan, akan berhenti jika data yang didapatkan sudah jenuh atau sudah tidak ada data yang dianggap baru lagi/ Taking technique informant snowball sampling depends on the key-informants, will stop if the data obtained was saturated or there is no data to be new again. 


\section{a. Biaya Pemasaran}

Besarnya biaya pemasaran lele dapat dihitung dengan menggunakan rumus sebagai berikut (Handayani dan Nurlaila, 2011) :

$\mathrm{Bp}=\mathrm{Bp} 1+\mathrm{Bp} 2+\mathrm{Bp} 3+\ldots \ldots . .+\mathrm{Bpn}$

Keterangan :

$\mathrm{Bp}$

: Biaya pemasaran lele

Bp1, Bp2, Bp3,...,Bpn : Biaya pemasaran lele tiap-tiap lembaga pemasaran lele

$1,2,3, \ldots . n \quad$ : Jumlah Lembaga

\section{b. Keuntungan Pemasaran}

Besarnya keuntungan pemasaran lele dapat dihitung dengan menggunakan rumus sebagai berikut (Handayani dan Nurlaila, 2011) :

$K p=K p 1+K p 2+K p 3+\ldots \ldots .+K p n$

Keterangan :

Kp : Keuntungan pemasaran lele

Kp1,Kp2,Kp3,...Kpn : keuntungan pemasaran tiaplembaga pemasaran lele

\section{c. Margin pemasaran}

Margin pemasaran adalah selisih harga ditingkat produsen dan tingkat konsumen. Secara sistematis margin pemasaran dirumuskan sebagai berikut (Handayani dan Nurlaila, 2011):

$\mathrm{Mp}=\mathrm{Pr}-\mathrm{Pf}$

Keterangan :

$\mathrm{Mp}$ : Margin pemasaran lele ( $\mathrm{Rp} / \mathrm{kg}$ )

$\mathrm{Pr}$ : Harga lele ditingkat konsumen ( $\mathrm{Rp} / \mathrm{kg})$

Pf : Harga lele yang diterima produsen (Rp/kg)

Margin yang diperoleh pedagang perantara dari sejumlah biaya pemasaran yang dikeluarkan dan keuntungan yang diterima oleh pedagang perantara dirumuskan sebagai berikut (Handayani dan Nurlaila, 2011):

$\mathrm{Mp}=\mathrm{Bp}+\mathrm{Kp}$

Keterangan :

$\mathrm{M} \mathrm{p}$ : Margin pemasaran lele ( $\mathrm{Rp} / \mathrm{kg}$ )

$\mathrm{Bp}$ : Biaya pemasaran lele ( $\mathrm{Rp} / \mathrm{kg})$

$\mathrm{Kp}$ : Keuntungan pemasaran lele (Rp/kg)

\section{d. Efisiensi Pemasaran}

Efisiensi pemasaran dalam saluran pemasaran dapat dihitung dengan nilai persentase dari persentase margin pemasaran dari masing-masing saluran pemasaran digunakan rumus sebagai berikut (Handayani dan Nurlaila, 2011):

\section{e. Persentase Margin Pemasaran}

$\mathrm{Mp}=(\mathrm{Pr}-\mathrm{Pf} / \mathrm{Pr}) \times 100 \%$

Keterangan :

$\mathrm{Mp}=$ Margin pemasaran

Pf = Harga ditingkat produsen (pembudidaya)

$\operatorname{Pr}=$ Harga ditingkat konsumen

\section{f. Bagian yang Diterima Produsen}

$\mathrm{F}=(1-\mathrm{M} / \operatorname{Pr}) \times 100 \%$

Keterangan :

$\mathrm{F}=$ Bagian yang diterima produsen (pembudidaya)

$\mathrm{Mp}=$ Margin pemasaran

$\operatorname{Pr}=$ Harga ditingkat konsumen

Efisiensi pemasaran secara ekonomi dapat diketahui dari besarnya bagian yang diterima produsen dan persentase margin pemasaran yang dinyatakan dalam persen (\%). Pemasaran lele dianggap efisien secara ekonomis apabila saluran pemasaran mempunyai nilai persentase 
margin pemasaran yang rendah, tetapi mempunyai nilai persentase bagian yang diterima produsen (farmer's share) tinggi. Menurut Rasyaf dalam Handayani dan Nurlaila (2011), bila bagian yang diterima produsen > 50\% maka pemasaran dikatakan efisien, dan bila bagian yang diterima produsen $<50 \%$ berarti pemasaran belum efisien.

\section{HASIL DAN PEMBAHASAN}

\section{KARAKTERISTIK SOSIAL EKONOMI PEMBUDIDAYA}

Usaha budidaya ikan lele di Kabupaten Boyolali tergolong dalam tipologi usaha budidaya kolam air tenang (KAT) dan tergolong dalam skala mikro dengan luas lahan rata-rata sebesar $32 \mathrm{~m}^{2}$. Menurut Azzarnuji (2011), jumlah pembudidaya ikan lele di Kabupaten Boyolali pada tahun 2011 sebanyak 243 orang sedangkan jumlah sampel yang diambil sebanyak 31 orang, dengan rincian 14 orang di Kecamatan Banyudono dan 17 orang di Kecamatan Sawit. Karakteristik sosial ekonomi pembudidaya di 2 (dua) kecamatan terdiri dari usia, pendidikan, pengalaman usaha, dan jumlah maupun status kepemilikan lahan.

\section{Usia Pembudidaya}

Usia pembudidaya berdasarkan Gambar 1 dapat diketahui bahwa 57\% responden pembudidaya di Kecamatan Banyudono dan Sawit, Kabupaten Boyolali berada pada usia yang produktif yaitu 36-45 tahun. Pada usia produktif pembudidaya diharapkan mampu menjalankan usaha budidaya lele dengan baik. Selain itu dengan usia yang produktif pembudidaya mampu mengembangkan budidaya lele sehingga mampu menambah penghasilan keluarga.

\section{Pendidikan Pembudidaya}

Pendidikan pembudidaya berdasarkan Gambar 2 dapat diketahui bahwa 50\% responden pembudidaya adalah tamat SLTA. Hal ini menunjukkan dengan tingkat pendidikan yang tinggi pembudidaya dapat memahami bagaimana cara budidaya lele yang baik dan mudah menyerap teknologi budidaya dari penyuluh perikanan. Tingkat pendidikan yang tinggi yang dimiliki responden pembudidaya dapat menjadi modal bagi pembudidaya dalam menjalankan usaha budidayanya serta dapat melakukan pemilihan saluran pemasaran yang baik dan menguntungkan bagi pembudidaya, sehingga pembudidaya dapat memperoleh keuntungan yang sebesar-besarnya.

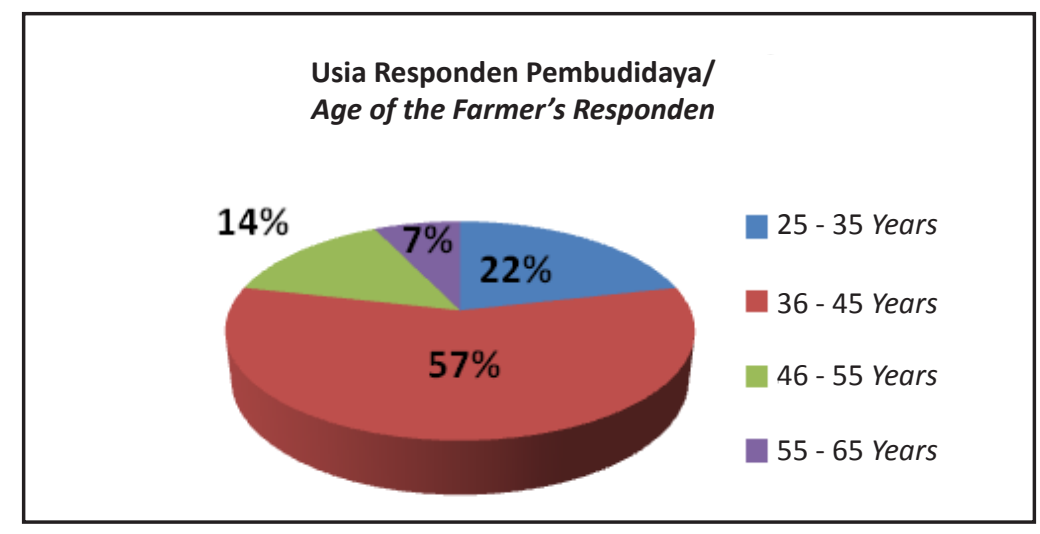

Gambar 1. Karakteristik Sosial Ekonomi Responden Pembudidaya Berdasarkan Usia di Kabupaten Boyolali, 2012.

Figure 1. Socio-economics Characteristic of Farmers Respondent by Age in Boyolali District, 2012.

Sumber : Data primer diolah, 2012/ Source :Primary data processed, 2012 


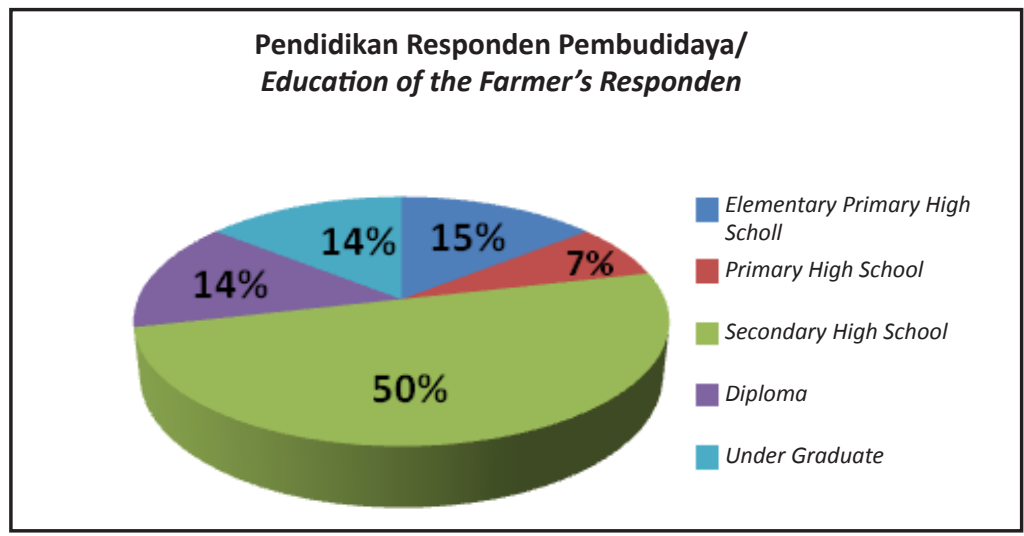

Gambar 2. Karakteristik Sosial Ekonomi Responden Pembudidaya Berdasarkan Pendidikan di Kabupaten Boyolali, 2012.

Figure 2. Socio-economics Characteristic of Farmers Respondent by Education in Boyolali District, 2012.

Sumber: Data primer diolah, 2012/ Source: Primary data processed, 2012

\section{Pengalaman Usaha Pembudidaya}

Keberhasilan usaha budidaya lele tidak hanya ditentukan oleh pendidikan saja tetapi juga ditentukan oleh pengalaman usaha dalam budidaya. Gambar 3 menunjukkan persentase pembudidaya berdasarkan pengalaman usaha budidaya lele di Kecamatan Tegalrejo dan Sawit Kabupaten Boyolali yaitu kurang dari 10 tahun. Pengalaman usaha pembudidaya menunjukkan lamanya waktu pembudidaya dalam usaha budidaya lele yang masih tergolong dalam kategori rendah. Berdasarkan pengalaman yang telah dimiliki oleh pembudidaya diharapkan kedepannya pembudidaya mampu lebih baik lagi untuk meningkatkan kualitas produksi ikan sehingga dapat mempertahankan serta meningkatkan skala usahanya, memperluas pemasaran ikan sehingga mampu meningkatkan pendapatannya.

\section{Pengalaman Usaha Responden Pembudidaya/ \\ Bussines Experience of the Farmer's Respondent}

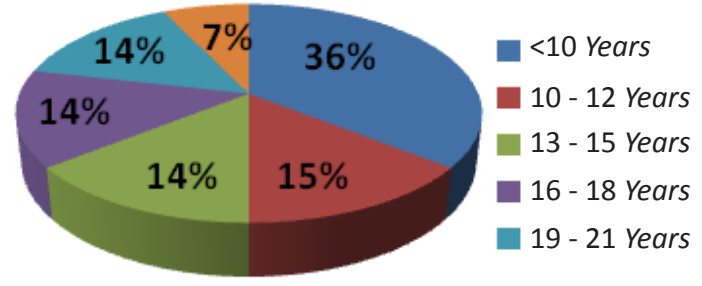

Gambar 3. Karakteristik Sosial Ekonomi Responden Pembudidaya Berdasarkan Pengalaman Usaha di Kabupaten Boyolali, 2012.

Figure 3. Socio-economics Characteristic of Farmer's Respondent by Business Experince in Boyolali District, 2012. 


\section{Jumlah dan Status Kepemilikan Lahan}

Banyaknya kepemilikan lahan budidaya lele (Gambar 4) menentukan besarnya pendapatan pembudidaya. Semakin luasnya lahan budidaya yang dimiliki oleh pembudidaya maka jumlah produksi ikan lele yang dihasilkan semakin banyak. Sehingga pendapatan pembudidaya semakin meningkat. Selain itu, kepemilikan lahan juga berpengaruh pada biaya (cost), karena sebagian besar status kepemilikan lahan budidaya adalah milik kelompok yakni bantuan dari program Pengembangan Usaha Mina Pedesaan (PUMP) maka biaya yang dikeluarkan lebih sedikit karena tidak ada biaya sewa lahan.

\section{KARAKTERISTIK SOSIAL EKONOMI LEMBAGA PEMASARAN LELE}

Lembaga pemasaran yang terlibat dalam pendistribusian ikan lele adalah pedagang pengumpul (dalam dan luar kabupaten), dan pedagang pengecer (dalam dan luar kabupaten). Karakteristik lembaga pemasaran ikan lele pada pedagang pengumpul terdiri dari dua orang pedagang di Kecamatan Banyudono dan Sawit dan dua pedagang pengumpul luar kabupaten (Kabupaten Sleman dan Semarang) mempunyai rata-rata usia 22 tahun sehingga dikategorikan dalam usia produktif. Usia sangat berpengaruh terhadap kemampuan mereka dalam menjalankan perannya sebagai lembaga penyalur dalam pemasaran ikan lele dari pembudidaya ke konsumen. Karakteristik lembaga pemasaran ikan lele pada pedagang pengecer di Kecamatan Banyudono dan Sawit dengan usia rata-rata 32 tahun, mempunyai tingkat pendidikan tinggi yakni tamat SLTA, dengan tingginya tingkat pendidikan yang dimiliki responden lembaga pemasaran diharapkan dapat mengambil keputusan dengan baik dalam berdagang serta mampu membaca infomasi pasar yang ada sehingga memperlancar proses pemasaran yang dilakukan. Pengalaman usaha pemasaran lele rata-rata selama 9 tahun. Dengan lamanya pengalaman usaha maka akan mudah bagi pedagang dalam memasarkan lele sehingga memperlancar proses pemasaran yang dilakukan. Lama usaha berdagang akan mempengaruhi pengalaman dalam memasarkan lele. Semakin lama usaha berdagang, semakin mudah bagi pedagang dalam memasarkan lele. Hal ini disebabkan, pedagang yang sudah lama menggeluti usaha pemasaran maka mereka akan lebih dikenal oleh konsumen sehingga jaringan pemasarannya akan semakin luas.

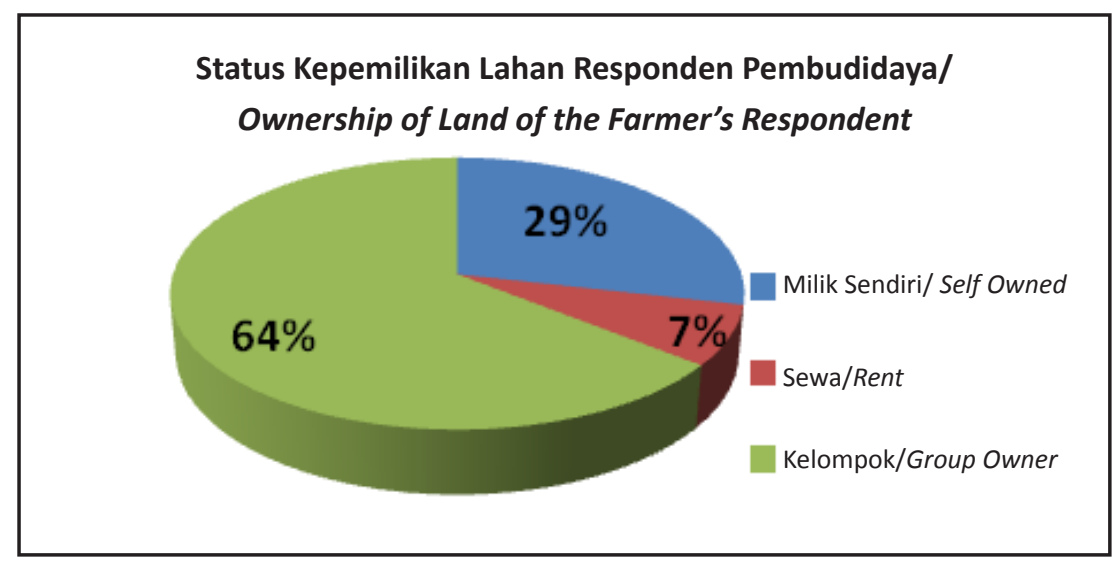

Gambar 4. Karakteristik Sosial Ekonomi Responden Pembudidaya Berdasarkan Status Kepemilikan Lahan di Kabupaten Boyolali, 2012.

Figure 4. Socio-economics Characteristic of Farmer's Respondent by Owner ship of Land in Boyolali District, 2012. 
Untuk fungsi pemasaran dari lembaga pemasaran yang ada, maka terlihat bahwa hanya pedagang pengumpul luar kabupaten yang melaksanakan ketiga fungsi pemasaran. Fungsi pertukaran meliputi pertukaran barang sehingga menciptakan hak milik. Untuk fungsi fisik, kegiatan yang dilakukan diantaranya adalah pengangkutan, bongkar muat, dan penyimpanan. Sedangkan fungsi pelancar terdiri dari standarisasi, grading, biaya, info pasar dan harga. Fungsi pemasaran dari lembaga pemasaran lele disajikan pada Tabel 2.

\section{RANTAI PEMASARAN LELE}

Porter (1985), memberikan pemahaman rantai nilai sebagai nilai sebuah kombinasi dari sembilan aktivitas operasi penambahan nilai umum dalam sebuah perusahaan. Fokus utama dalam rantai nilai terletak pada keuntungan yang ditambahkan kepada konsumen, proses saling tergantung dan menghasilkan nilai dan permintaan yang dihasilkan serta arus dana yang dibuat (Fele, Shunk dan Callarman, 2012). Rantai nilai pada usaha perikanan budidaya dengan komoditas lele dapat mencakup input produksi (benih), pembudidaya atau produsen (untuk membudidayakan dan memasarkan lele), pengolahan lele, pedagang pengumpul dan pedagang pengecer yang mengirimkan produk ke pedagang grosir dan pasar lainnya, dan konsumen yang membeli lele dalam berbagai bentuk hidup maupun produk olahan.

Di Kabupaten Boyolali analisis rantai nilai terhadap berbagai rantai pasokan dilakukan berdasarkan saluran pemasaran yang digunakan oleh pembudidaya untuk menjual hasil produksi mereka. Dengan demikian, ada 4 (empat) rantai tata niaga lele di Kabupaten Boyolali sebagai berikut:

Saluran 1 : Pembudidaya $\rightarrow$ pedagang pengumpul kabupaten $\rightarrow$ pedagang pengecer kabupaten $\rightarrow$ konsumen akhir

Saluran 2 : Pembudidaya $\rightarrow$ pedagang pengumpul luar kabupaten $\rightarrow$ pedagang pengecer luar kabupaten $\rightarrow$ konsumen luar kabupaten

Saluran 3 : Pembudidaya $\rightarrow$ pedagang pengecer kabupaten $\rightarrow$ konsumen akhir kabupaten

Saluran 4 : Pembudidaya $\rightarrow$ pengolah hasil perikanan $\rightarrow$ konsumen akhir kabupaten dan luar kabupaten

Hal ini sama dengan hasil penelitian Fauzi (2008) dan Puspitasari (2010) yang menyatakan bahwa ada 4 (empat) pola saluran pemasaran lele baik jenis sangkuriang maupun dumbo di Kabupaten Bogor dan Cirebon dengan penjualan dalam keadaan hidup di tiga saluran pemasaran dan produk olahan di satu saluran pemasaran. Berdasarkan keempat saluran rantai

Tabel 2. Fungsi Pemasaran dari Lembaga Pemasaran Lele di Kabupaten Boyolali, 2012. Table 2. Marketing Function of Catfish Marketing Institution in Boyolali District, 2012.

\begin{tabular}{lccc}
\hline & \multicolumn{3}{c}{ Lembaga Pemasaran/Market Institution } \\
\cline { 2 - 4 } \begin{tabular}{l} 
Mungsi Pemasaran/ \\
\cline { 2 - 4 }
\end{tabular} & $\begin{array}{c}\text { Pedagang Pengumpul } \\
\text { Kabupaten/Middleman } \\
\text { in District level }\end{array}$ & $\begin{array}{c}\text { Pedagang Pengumpul } \\
\text { Luar Kabupaten/ } \\
\text { Middleman in Outside } \\
\text { the District Level }\end{array}$ & $\begin{array}{c}\text { Pedagang Pengecer } \\
\text { Kabupaten/Retailers } \\
\text { in District Level }\end{array}$ \\
\hline $\begin{array}{l}\text { Fungsi pertukaran } \\
\text { (Exchange function) }\end{array}$ & $\mathrm{Ya} /$ Yes & $\mathrm{Ya} /$ Yes & Ya/Yes \\
$\begin{array}{l}\text { Fungsi fisik } \\
\text { (Physical function) }\end{array}$ & $\mathrm{Ya} /$ Yes & $\mathrm{Ya} /$ Yes & Tidak/No \\
$\begin{array}{l}\text { Fungsi pelancar } \\
\text { (Facilitating function) }\end{array}$ & Tidak/No & $\mathrm{Ya} /$ Yes & Tidak/No \\
\hline
\end{tabular}

Sumber : Data primer diolah, 2012/ Source: Primary data of processed, 2012 
pemasaran lele di Kabupaten Boyolali, dimulai dari hulu (pembudidaya) dan berakhir di hilir (konsumen akhir). Oleh karena produksi lele mayoritas dijual dalam bentuk ikan hidup dan masih sedikit dalam bentuk olahan, maka dari ke seluruh rantai, berakhir pada pada konsumen akhir yaitu konsumen rumah tangga. Pangsa pasar tebesar lele Kabupaten Boyolali adalah Yogjakarta dan saat ini mulai berkembang sampai dengan kota Semarang di samping kota-kota disekitar Boyolali.

Beberapa pembudidaya bertindak merangkap sebagai pedagang pengumpul dan mayoritas pembudidaya tidak merangkap sebagai pembenih. Benih lele dapat dipenuhi dari dalam Kabupaten Boyolali, namun demikian masih banyak benih lele yang dipasok dari luar kabupaten dan berasal dari Kabupaten Tulungagung. Benih yang digunakan rata-rata berukuran 7 dan 8 dengan harga berkisar Rp 100 - Rp 125 per ekor. Benih lele kemudian dibesarkan oleh pembudidaya dengan media kolam tanah dan kemudian disaluran pemasaran kepada pedagang pengumpul kabupaten (38\%), pengumpul luar kabupaten (38\%), pedagang pengecer (22\%) dan pengolah (2\%). Masing-masing segmen saluran pemasaran telah mempunyai pelanggan untuk dijual dengan sistem pembayaran dilakukan secara berjangka untuk beberapa saluran pasar. Persentase distribusi lele ke pedagang pengumpul di kabupaten sama dengan pedagang pengumpul luar kabupaten, hal ini berarti jumlah permintaan untuk konsumsi lele di Kabupaten Boyolali sama dengan Kabupaten DIY dan Semarang.

Pedagang pengumpul kabupaten menjual lele kepada pengumpul luar kabupaten (76\%) dan sebagian lagi kepada pedagang pengecer kabupaten (24\%). Pedagang pengumpul luar kabupaten adalah mayoritas pedagang pengumpul di Jogjakarta. Pedagang pengecer biasanya berjualan di pasar-pasar tradisional dan menjual kepada konsumen akhir yaitu konsumen rumah tangga dan lembaga (100\%). Rantai pasok dan rantai pemasaran lele pada setiap simpul pelaku usaha disajikan dalam Gambar 5 dan 6.

\section{MARGIN DAN KEUNTUNGAN DALAM RANTAI PEMASARAN LELE}

Proses mengalirnya barang dari pembudidaya ke konsumen memerlukan biaya, dengan adanya biaya pemasaran maka suatu produk akan lebih tinggi harganya. Semakin panjang rantai pemasaran maka biaya yang dikeluarkan dalam pemasaran akan semakin meningkat. Untuk mengetahui besarnya biaya, keuntungan dan marjin pemasaran lele pada keempat rantai pemasaran di Kabupaten Boyolali dapat dilihat pada Gambar 6 .

Berdasarkan Gambar 6, pada saluran pemasaran I harga rata-rata ikan lele yang dibayar oleh pedagang pengumpul kabupaten ke pembudidaya pada waktu penelitian sebesar Rp 10.700 per kg, harga yang dibayarkan oleh pedagang pengumpul kabupaten tergantung informasi harga dan dalam pelaksanaannya belum ada standar sehingga masih terjadi fluktuasi harga, dengan pembayaran ke pembudidaya secara tunai (cash). Selama proses pemasaran, biaya transportasi dan biaya penanggulangan resiko ditanggung oleh pedagang pengumpul.

Pangsa pasar lele terbesar Kabupaten Boyolali adalah Daerah Istimewa Yogyakarta (DIY) dan saat ini berkembang sampai kota Semarang. Hampir setiap hari pedagang pengumpul kabupaten menyetor produk ke padagang berikutnya di sekitar DIY dalam bentuk ikan hidup. Pembudidaya pengumpul lokal biasanya merangkap sebagai pembudidaya dan mempunyai mitra binaan. Pedagang pengumpul lokal biasanya mempunyai beberapa langganan dengan kapasitas penjualan perhari sebesar 1 ton. Biaya-biaya yang dikeluarkan untuk usaha pengumpul lokal antara lain biaya investasi (blong/tempat ikan, keranjang, serokan dan timbangan) dan biaya operasional (pembelian lele, transportasi, biaya tenaga kerja, biaya penanggulangan resiko, biaya penyusutan dan sewa kendaraan) dengan jumlah total biaya sebesar Rp 383 per kg. Sehingga diperoleh marjin pemasaran pedagang pengumpul lokal sebesar Rp 917 per kg. 


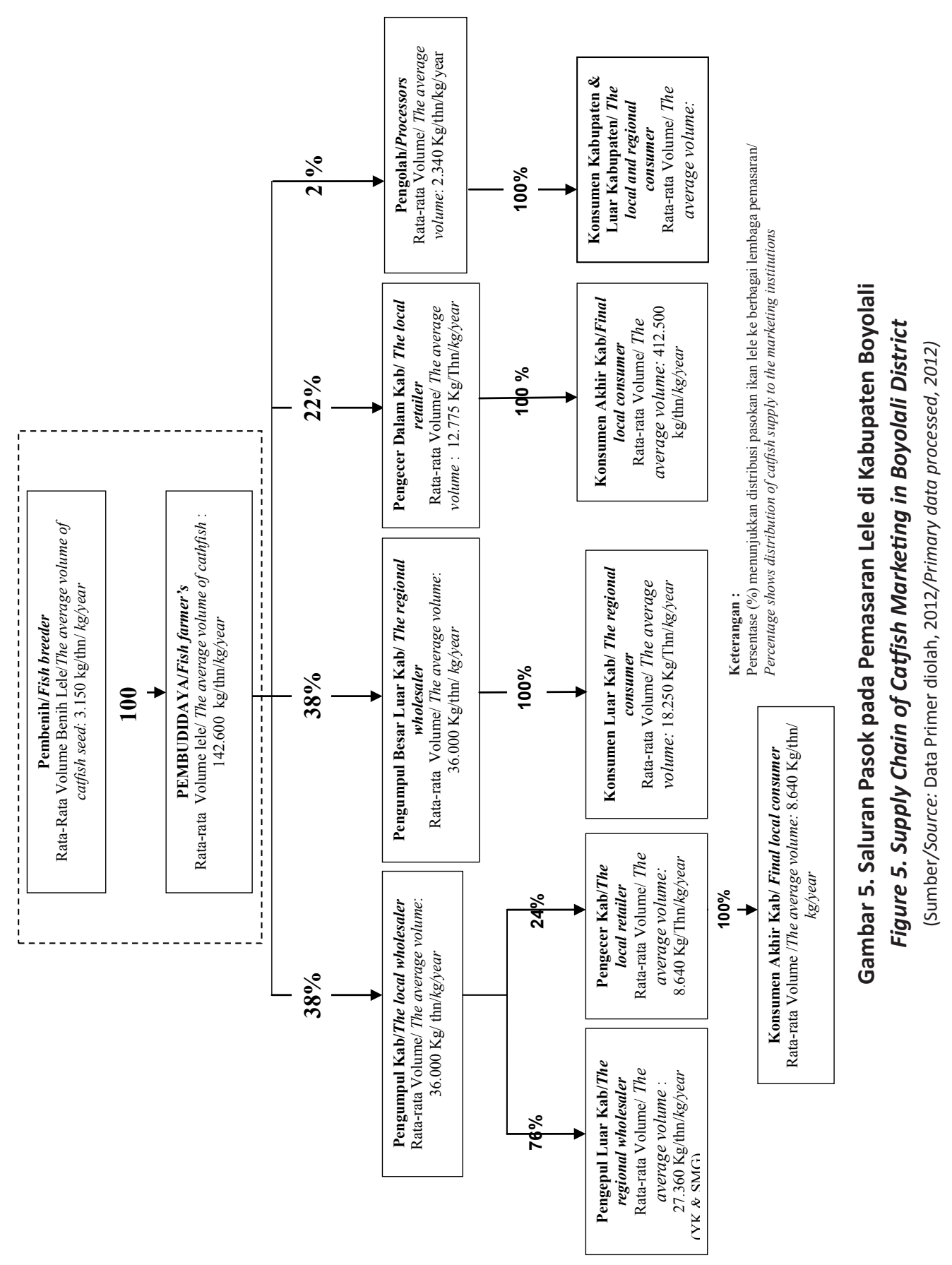




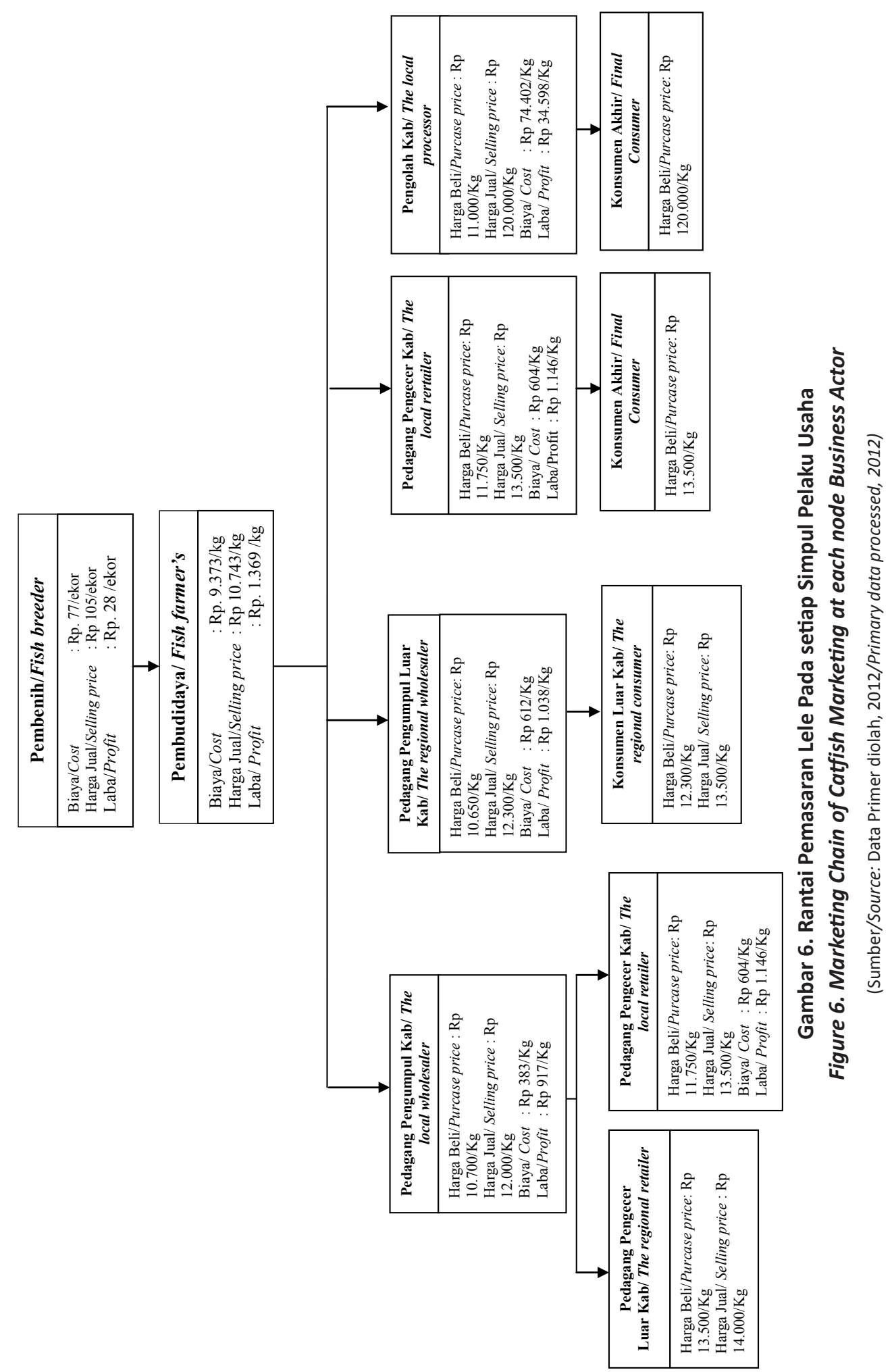


Pedagang pengumpul lokal kabupaten menjual ikan lele ke pedagang pengecer kabupaten maupun luar kabupaten. Harga jual lele di tingkat pedagang pengecer luar kabupaten lebih tinggi daripada pedagang pengecer dalam kabupaten, dengan selisih harga sebesar Rp 1.750 per kg. Tingginya harga jual lele ke pedagang pengumpul luar kabupaten disebabkan kondisi permintaan dan penawaran pasar.

Farmer's share merupakan bagian yang diterima pembudidaya atau perbandingan antara harga yang diterima pembudidaya/ produsen dengan harga yang diterima konsumen. Menurut Roziah (2005) dalam Sobirin (2009), pola pemasaran yang paling efisien secara ekonomi memiliki marjin terkecil dan farmer's share terbesar diantara pola pemasaran lainnya. Berdasarkan empat saluran pemasaran (Gambar 7), terlihat bahwa farmer's share pada saluran pemasaran I dan Il lebih besar yaitu 87,34 \% daripada saluran pemasaran III dan IV sehingga dapat dikatakan efisien secara ekonomi. Rata-rata biaya, keuntungan, marjin pemasaran dan bagian yang diterima produsen ikan lele di Kabupaten Boyolali pada keempat saluran pemasaran dapat dilihat pada Gambar 6. Bardasarkan Gambar 6 dapat diketahui bahwa saluran pemasaran I, produsen melibatkan peranan dua lembaga pemasaran yaitu pedagang pengumpul dan pengecer, sedangkan pada saluran II melibatkan peranan satu lembaga pemasaran yaitu pedagang pengumpul. Sebagian besar produsen menggunakan saluran pemasaran I dan II karena bagian yang diterima oleh pembudidaya lebih banyak, sehingga meningkatkan pendapatan bagi pembudidaya sebagai produsen.

\section{EFISIENSI PEMASARAN LELE}

Menurut Mubyarto (1995), analisis pemasaran dianggap efisien apabila dianggap mampu menyampaikan hasil dari produsen kepada konsumen dengan biaya wajar serta mampu mengadakan pembagian yang adil dari keseluruhan harga yang dibayarkan konsumen.

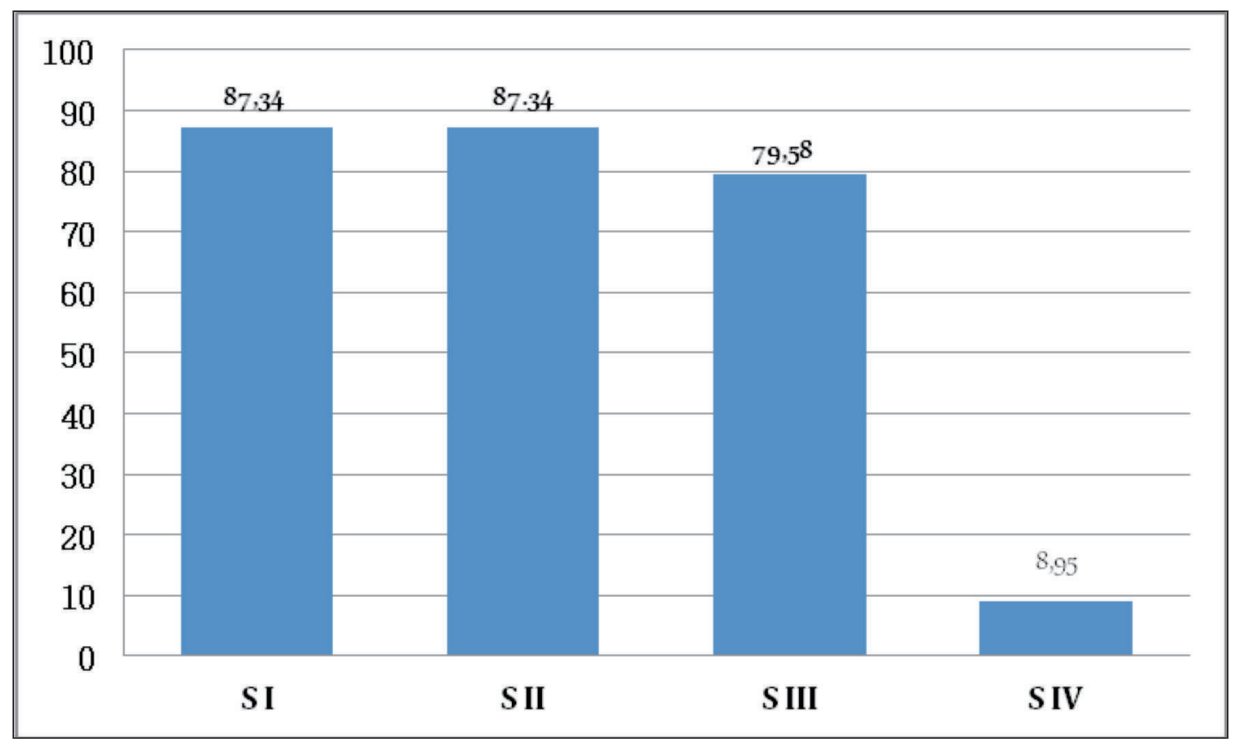

Gambar 7. Bagian yang diterima Produsen Pada Rantai Pemasaran Ikan Lele di Kabupaten Boyolali.

Figure 7. Farmer's Share of Catfish Marketing Chain in Boyolali District.

(Sumber: Data Primer diolah, 2012/ Source: Primary data processed, 2012) 
Tabel 3. Efisiensi Ekonomi Rantai Pemasaran Ikan Lele di Kabupaten Boyolali, 2012. Table 3. Economics Efficiency of Catfish Marketing Chain in Boyolali District, 2012.

\begin{tabular}{lrrrr}
\hline \multicolumn{1}{c}{$\begin{array}{c}\text { Saluran Pemasaran/ } \\
\text { Marketing Channel }\end{array}$} & \multicolumn{1}{c}{$\begin{array}{c}\text { Saluran I/ } \\
\text { Channel I }\end{array}$} & $\begin{array}{l}\text { Saluran II/ } \\
\text { Channel II }\end{array}$ & $\begin{array}{l}\text { Saluran III/ } \\
\text { Channel III }\end{array}$ & $\begin{array}{r}\text { Saluran IV/ } \\
\text { Channel IV }\end{array}$ \\
\hline $\begin{array}{l}\text { Total Biaya/ } \\
\text { Total Cost (Rp/kg) }\end{array}$ & 10,360 & 9,985 & 9,977 & 83,775 \\
$\begin{array}{l}\text { Total Keuntungan/ } \\
\text { Total Profit (Rp/kg) }\end{array}$ & 3,432 & 2,407 & 2,515 & 35,967 \\
$\begin{array}{l}\text { Margin pemasaran/ } \\
\text { Marketing margin (Rp/kg) }\end{array}$ & 2,757 & 1,557 & 2,757 & 1,257 \\
Farmer's Share (\%) & 79.58 & 87.34 & 79.58 & 8.95 \\
\hline
\end{tabular}

Sumber : Data Primer diolah, 2012/Source: Primary data processed, 2012

Untuk mengetahui efisiensi pemasaran lele secara ekonomis adalah dengan melihat marjin dan bagian yang diterima pembudidaya (farmer's share) pada setiap saluran pemasaran yang ada. Efisiensi ekonomis pemasaran lele di Kabupaten Boyolali dapat dilihat pada Tabel 3, dimana saluran pemasaran III dan IV memiliki marjin pemasaran yang lebih tinggi dibandingkan saluran pemasaran I dan II. Hal ini karena pada saluran pemasaran I jumlah ikan yang diperjualbelikan banyak dengan biaya yang tinggi karena sudah mengalami pengolahan ikan. Tingginya biaya disebabkan karena proses pengolahan ikan sehingga dapat memberikan nilai tambah terhadap produk ikan lele. Penetapan tingkat keuntungan yang tinggi menyebabkan rendahnya margin dan keuntungan pemasaran, serta nilai bagian yang diterima produsen semakin rendah Berdasarkan tinggi rendahnya marjin pemasaran dan farmer's share, maka saluran pemasaran I, II, dan III efisien secara ekonomis di Kabupaten Boyolali. Hal ini dikarenakan nilai farmer's share dari saluran pemasaran I, II, dan III lebih dari $50 \%$, sedangkan saluran IV tidak efisien karena meskipun margin pemasarannya rendah, namun farmers share nya juga rendah karena bagian yang diterima oleh pembudidaya lebih kecil daripada bagian yang diterima oleh pengolah.

Menurut penelitian Fauzi (2008) dan Puspitasari (2010) margin terbesar terdapat pada saluran pemasaran dengan penjualan dalam bentuk olahan, sedangkan yang ditemui di Kabupaten Boyolali, margin pemasaran terbesar di saluran pemasaran dengan penjualan dalam bentuk hidup. Untuk farmer's share nilai terkecil menurut Fauzi (2008) dan Puspitasari (2010) ada pada penjualan lele dengan bentuk olahan, hal ini sama dengan penelitian di Kabupaten Boyolali. Secara umum pada empat pola saluran pemasaran lele di Kabupaten Boyolali, Kabupaten Bogor dan Kabupaten Cirebon menunjukkan relatif efisiensi secara ekonomi.

\section{KESIMPULAN DAN IMPLIKASI KEBIJAKAN}

\section{Kesimpulan}

Saluran pemasaran lele di Kabupaten Boyolali terdiri dari 4 (empat) pola saluran pemasaran. Sifat produk yang dijual mulai dari pembudidaya hingga ke pedagang pengecer sama (homogen) pada saluran I-III sedangkan untuk saluran IV bersifat berbeda karakteristik (deferensiasi). Panjang pendeknya saluran pemasaran dipengaruhi oleh biaya, harga dan efisiensi ekonomis pemasaran. Jika harga yang ditawarkan pedagang/lembaga tataniaga semakin tinggi dan kemampuan konsumen dalam membayar harga semakin tinggi, maka bagian yang diterima oleh pembudidaya akan semakin sedikit. Margin pemasaran berhubungan negatif dengan bagian yang diterima produsen (farmers share). 
Semakin tinggi margin pemasaran, maka farmers share semakin rendah. Saluran II tergolong paling efisien untuk saluran pemasaran ikan lele hidup, berbeda dengan industri pengolahan (saluran IV) yang memiliki farmers share sangat kecil yaitu 8,95\%, namun memiliki potensi yang besar untuk dikembangkan dalam rangka peningkatan nilai tambah dan pendapatan masyarakat khususnya pembudidaya dan industri pengolahan.

Salah satu usaha untuk peningkatan nilai dan mengoptimalkan pemanfaatan hasil perikanan budidaya adalah dengan mengembangkan produk bernilai tambah baik olahan tradisional maupun modern. Usaha perikanan budidaya cukup berkembang namun belum diimbangi dengan pengembangan pengolahannya yang memadai. Saat ini produk perikanan budidaya masih dalam bentuk ikan hidup, segar dan beku. Hal ini dikarenakan kurangnya kontinuitas bahan baku untuk industri pengolahan, rendahnya standar bahan baku, skala produksi industri pengolahan perikanan yang masih mikro dan kecil (produksi tergantung pesanan), lemahnya jaminan mutu dan keamanan hasil perikanan (quality assurance and food safety), kurangnya intensitas promosi, jenis produk dan pengembangan produk bernilai tambah belum berkembang, belum berkembangnya teknologi pengemasan (packaging) produk olahan hasil perikanan.

\section{Implikasi Kebijakan}

Untuk mendukung industri perikanan budidaya yang maju dan bernilai tambah maka strategi kebijakan yang dapat dipertimbangkan antara lain : (1) Memastikan setiap unit industri pengolahan lele mempunyai pasokan bahan baku yang kontinu dan sesuai kebutuhan; (2) Pengembangan diversifikasi produk olahan hasil perikanan yang berdaya saing; (3) Sertifikasi mutu produk olahan perikanan berdasarkan konsep Hazard Analytic Critical Control Point (HACCP); dan (4) Penyempurnaan sistem informasi pemasaran perikanan budidaya.

\section{DAFTAR PUSTAKA}

Anonim. 2010. Statistik Perikanan Budidaya. Direktorat Jenderal Perikanan Budidaya. Jakarta.

. 2012. Perikanan Kabupaten Boyolali Tahun 2007- 2011. Dinas Peternakan dan Perikanan Kabupaten Boyolali. Boyolali.

Az-zarnuji, A.T. 2011. Analisis Efisiensi Budidaya Ikan Lele di Kabupaten Boyolali (Studi Kasus di Kecamatan Sawit Kabupaten Boyolali. Skripsi. Universitas Diponegoro. Semarang.

Fauzi, S. 2008. Analisis Efisiensi Pemasaran Ikan Lele di Kecamatan Kapetakan, Kabupaten Cirebon. Skripsi. Institut Pertanian Bogor. Bogor.

Feller, A., Shunk, D, and T. Callarman, 2006. Value Chains Versus Supply Chains. BPTrends. http://www.ceibs.edu/knowledge/papers/ images/20060317/2847.pdf. Di Akses Tanggal 25 Januari 2012.

Handayani, S.M dan I. Nurlaila. 2011. Analisis Pemasaran Lele di Kabupaten Klaten. Jurnal Sains Peternakan 9 (1) Jurusan Peternakan Universitas Sebelas Maret. Surakarta.

Juanda, B. 2007. Metodologi Penelitian Ekonomi dan Bisnis. IPB Press. Bogor.

Mubyarto . 1995. Pengantar Ekonomi Pertanian. LP3ES. Jakarta.

Porter, M. 1985. Competitive Advantage, Creating and Sustaining Superior Performance. The Free Press. New York.

Puspitasari, E.Y. 2010. Analisis Efisiensi Tataniaga pada Kelompok Usaha Budidaya Ikan Lele Sangkuriang (Clarias Sp.) di Kecamatan Ciawi, Kabupaten Bogor, Provinsi Jawa Barat. Skripsi. Institut Pertanian Bogor. Bogor.

Raharjo, A. 2012. 7 (Tujuh) Provinsi Penghasil Ikan Lele. http://benihikan.net/lele/7tujuh-provinsi-penghasil-ikan-lele/. Di Akses Tanggal 12 September 2012. 
Sobirin, T. 2009. Efisiensi Pemasaran Pepaya (Carica papaya L.) di Kecamatan Subang Kabupaten Banyumas. Skripsi. Universitas Jenderal Soedirman. Purwokerto. 